\title{
INTEGRALIDADE: DISPOSITIVO PARA A FORMAÇÃO CRÍTICA DE PROFISSIONAIS DE SAÚDE
}

\author{
INTEGRALITY: A TOOL FOR THE CRITICAL TRAINING \\ OF HEALTH PROFESSIONALS
}

José Paulo Vicente da Silva 1

Cláudia Mara de Melo Tavares 2

Resumo Propõe-se neste artigo uma reflexão sobre o uso do conceito de integralidade como dispositivo de abordagem crítica na formação de profissionais de saúde. Coloca-se em destaque a escuta das necessidades de saúde, como um meio para construção de uma prática de cuidar participativa, ética, solidária e centrada no vínculo. Frente ao contexto analisado, aponta-se como desafio para a formação em saúde: a conscientização dos profissionais para atuarem criticamente face ao processo de responsabilização e comunicação dialógica entre governantes, gestores, usuários, instituições formadoras e demais setores da sociedade, visando a integralidade da atenção em saúde.

Palavras-chave formação profissional em saúde; integralidade; cuidado.
Abstract In this article we propose to reflect upon the use of the concept of "integrality" as a tool in the training of health professionals. We give special attention to the need to listen to health demands, as they must be the basis for the construction of care practices that are participatory, ethical, sympathetic and centred on relationships. The results of the analysis suggest that the main challenges for the training of health professionals are: to develop the professionals' awareness of the need to act critically when faced with the need to attribute responsibilities and to establish a dialogue between governing bodies, managers, users, training institutions and other sectors of society, in an attempt to seek the integrality of health care.

Key words professional training in health; integrality; care. 


\section{Introdução}

Desde a instituição do Sistema Único de Saúde (SUS) na Constituição Federal de 1988, experimentam-se grandes avanços no âmbito das políticas públicas de saúde. Aproximadamente sessenta milhões de homens e mulheres, antes considerados "indigentes sanitários", se transformaram, ao menos em tese, em cidadãos portadores de direito à saúde. Essa constitui a maior conquista da Reforma Sanitária Brasileira. Programas de saúde pública, como é o caso do programa de controle de DST/Aids, vêm logrando importantes resultados, alcançando, inclusive, reconhecimento em âmbito internacional. A disseminação dos mecanismos de controle social, materializados em Conselhos Locais, Municipais, Estaduais e no Conselho Nacional de Saúde mobilizam milhares de cidadãs e cidadãos e contribuem para a acumulação do capital social em nosso País (Mendes, 2001).

O processo de descentralização da política de saúde vem proporcionando a transferência de serviços, responsabilidades, poder e recursos, da esfera federal, para as esferas estadual e municipal. Sobretudo, após o processo de municipalização, constata-se uma considerável expansão das redes de serviços e ações de saúde, bem como uma efetiva ampliação da capacidade gestora do sistema, fator que vem possibilitando uma expressão crescente de importantes e diversas experiências inovadoras nos campos da gestão e do cuidado à saúde.

Esses avanços, entretanto, ainda que extremamente importantes, estão longe de expressar a profunda e necessária transformação para que o SUS se torne um sistema de saúde efetivamente universal, igualitário, resolutivo e humanizado, e que, portanto, seja capaz de responder às necessidades de saúde, incidindo na melhoria das condições de saúde e vida da população brasileira.

Tal transformação depende da superação de uma série de obstáculos relacionados à organização da macropolítica setorial, exigindo uma mudança substantiva nos modos de se produzir o cuidado à saúde no âmbito dos serviços de saúde, tendo em vista que a organização dos processos de trabalho constitui um dos principais pontos críticos do sistema de saúde.

A discussão sobre a formação profissional passa a ser fundamental e estratégica quando falamos do SUS, que, sob a responsabilidade das três esferas de governo, a federal, a estadual e a municipal, operam o sistema de saúde, realizando ações e serviços em prol da saúde da população. Para tanto, além de estarem capacitados do ponto de vista profissional, técnico, psicológico, político e humanístico, os trabalhadores da saúde devem estar protegidos por uma política de gestão do trabalho justa e coerente.

O plano de reorientação da política de gestão do trabalho no SUS preconiza a educação permanente no trabalho visando alcançar perfis profis- 
sionais orientados pelas necessidades da população, em cada realidade regional e em cada nível de complexidade, apontando que esta qualificação se dá frente às ações concretas do mundo do trabalho. Esta lógica de formação, contudo, parece estar distante de uma proposta de educação de base crítica e libertadora, que pressupõe o compromisso com a formação integral do ser, ampliando sua capacidade de compreensão, análise e escolha, deixando-o em melhor condição para o exercício da cidadania e da solidariedade.

Entendemos que, embora seja importante considerar o trabalho como um princípio educativo, a formação de profissionais de saúde não se deve pautar exclusivamente nas exigências do mundo do trabalho, atendendo a uma lógica produtivista do mercado. Se o SUS busca construir, com base em seus princípios, relações solidárias e democráticas, os modos de formação empregados para a qualificação de seus profissionais deve pressupor o desenvolvimento omnilateral das capacidades humanas. Sem uma formação crítica e ampliada, o trabalhador de saúde não poderá verdadeiramente compreender a saúde como uma produção social nem a complexidade do seu fazer a partir da escuta das necessidades da população.

Neste artigo, tomaremos o princípio da integralidade como dispositivo crítico para a formação de profissionais de saúde, ressaltando o seu potencial para o trabalhador operar transformações na política de saúde. Compreendemos que, como os demais princípios do SUS, o princípio da integralidade só se materializa no campo das relações humanas, nas relações políticas, nas relações de trabalho, na forma como os profissionais se relacionam com as pessoas que procuram os serviços de saúde.

\section{A organização do trabalho em saúde no contexto do modelo médico hegemônico}

Historicamente, o trabalho em saúde vem sofrendo forte influência das organizações produtivas hegemônicas, como o taylorismo e o fordismo. No Brasil, a taylorização do processo de trabalho nos serviços públicos de saúde se deu por meio do desenvolvimento de linhas de produção e da divisão do trabalho entre profissionais com diferentes formações e treinamentos alguns desses trabalhadores executando atividades simples e repetitivas, enquanto os médicos ficariam responsáveis somente pelo trabalho intelectual (Campos, 1991).

Nesse tipo de organização, o trabalho do médico, assim como, em menor escala, o trabalho de outros profissionais da equipe de saúde, como o dos dentistas e psicólogos, dentre outros, conservou um certo caráter artesanal. A incorporação de tecnologia de ponta e o acentuado processo de especialização, por mais paradoxal que possa parecer, não limitou de forma 
significativa a manutenção relativa da autonomia e da independência desses profissionais (Campos, 1991).

Entretanto, essa progressiva especialização do trabalho médico leva a uma fragmentação do processo terapêutico e dificulta um atendimento integral, já que cada especialista responsabiliza-se por uma parte do tratamento, compartimentalizando o sujeito. A grande autonomia do médico, bem como a sua preponderância sobre os demais profissionais, são fatores que vêm contribuindo de forma determinante para a fragilização do trabalho em equipe e, conseqüentemente, de qualquer trabalho multiprofissional cooperativo, solidário e integrado. Como resultado dessa fragmentação, tem-se a descontinuidade do processo de trabalho, com todos os prejuízos possíveis para a eficácia e para a qualidade dos serviços de saúde (Campos, 1991).

Esse tipo de organização do processo de trabalho em saúde vem operando, ao longo do tempo, na conformação e reprodução do modelo médico-hegemônico. O referido modelo de atenção estrutura-se a partir do saber médico hegemônico produtor de procedimentos e se desenvolveu a partir de interesses corporativos, sobretudo, dos grupos econômicos que atuam no setor saúde, em detrimento das necessidades de saúde da população. No plano da micropolítica do trabalho em saúde, esse modelo produziu uma organização do trabalho voltada à intervenção médica. Nesse tipo de organização, o saber médico hegemônico estrutura o trabalho dos outros profissionais da equipe de saúde, o que torna a produção do cuidado dependente de tecnologias duras 3 e leve-duras 4 (Merhy e Franco, 2003).

Entretanto, o trabalho em saúde é eminentemente relacional5, pois depende de 'trabalho vivo' em ato, ou seja, o trabalho no momento em que se está produzindo. Quando se dá o encontro entre o trabalhador e o usuário dos serviços de saúde, essas relações podem ser sumárias e burocráticas, sendo a assistência saúde produzida centrada no ato prescritivo. Tais relações compõem-se sobre um modelo cuja origem está no saber médico hegemônico, produtor de procedimentos. De forma antagônica, as relações entre profissional e usuário podem se dar como relações intercessoras 6 estabelecidas no trabalho vivo em ato, realizado no cuidado à saúde. Merhy (1997, 2002) denomina, a estas, tecnologias leves, pelo seu caráter relacional, que as situa como uma nova forma de agir entre sujeitos trabalhadores e usuários, individuais e coletivos, implicados com a produção do cuidado. O autor cita como exemplo de tecnologias leves do trabalho em saúde aquelas forjadas por meio das práticas de acolhimento, vínculo, autonomização, dentre outras.

Atualmente, no contexto de reestruturação dos processos produtivos globais, desenvolvem-se vários processos de reestruturação produtiva da saúde ${ }^{7}$ em nosso país. Contudo, as mudanças observadas no processo de trabalho não chegam a alterar de maneira estrutural o modo de se produzir 
saúde. A produção do cuidado permanece, portanto, centrada nas tecnologias duras e leve-duras, revelando a manutenção e a vigência do modelo médico hegemônico (Merhy, 2002; Merhy e Franco, 2003).

\section{A integralidade como dispositivo (re)estruturante do processo de trabalho e do cuidado em saúde}

A integralidade da atenção se apresenta como um importante dispositivo instituinte do processo de trabalho em saúde, com vistas a uma produção do cuidado eficaz, humanizada e, portanto, efetivamente centrada nas necessidades dos usuários individuais e coletivos dos serviços de saúde.

De acordo com CF de 1988, “a saúde é direito de todos e dever do Estado, garantido mediante políticas sociais e econômicas que visem à redução do risco de doenças e outros agravos e ao acesso universal e igualitário às ações e serviços para sua promoção, proteção e recuperação". Antes da institucionalização do SUS, o acesso aos serviços e às ações de saúde só estava garantido aos contribuintes do sistema previdenciário. Neste sentido, a CF assegura legalmente a atenção à saúde como direito de cidadania a todo o povo brasileiro.

Em consonância com o princípio da universalidade do acesso, o texto constitucional para a sua organização segundo as seguintes diretrizes: descentralização, com direção única em cada esfera de governo; atendimento integral, com prioridade para as atividades preventivas, sem prejuízo dos serviços assistenciais; e participação da comunidade.

A integralidade - termo que tem sido usado de forma corrente como referência à diretriz da atenção integral - deve ter sua leitura combinada com o princípio da igualdade da assistência. Em contraposição ao antigo sistema de saúde - o qual continha a dicotomia entre ações e serviços preventivos de cunho coletivo que eram realizados pelo Ministério da Saúde (MS), e as ações e serviços assistenciais de cunho individual, que eram implementados pelo Ministério da Previdência e Assistência Social (MPAS), através do Instituto Nacional de Previdência e Assistência Social (INAMPS) 一, o SUS deve combinar de forma harmônica e igualitária a cobertura desses serviços à totalidade da população, na direção da superação de tal dicotomia.

Então, do ponto de vista jurídico-institucional, a integralidade é definida como um conjunto articulado de ações e serviços de saúde, preventivos e curativos, individuais e coletivos nos diversos níveis de complexidade do sistema.

A aplicação do princípio da integralidade implica reconhecer, em primeiro lugar, que as redes de serviços de saúde devem operar de forma articulada segundo os mesmos princípios e as mesmas diretrizes no sentido de 
oferecer as ações de promoção, de prevenção, de cura e de reabilitação de doenças de acordo com as necessidades de saúde individuais e coletivas da população e, em segundo lugar, que as intervenções de um sistema de saúde sobre o processo saúde-doença conformam uma totalidade que engloba os sujeitos do sistema de saúde e suas inter-relações com os ambientes natural e social (Mendes, 1993).

Para tanto, a integralidade da atenção requer uma intervenção integradora, no seu âmbito tecnológico sobre os indivíduos, as famílias, os ambientes coletivos, os grupos sociais e o meio ambiente.

Outrossim, no que diz respeito à superação das desigualdades, que se referem aos diferentes padrões de saúde dos diversos grupos populacionais gerados pelo modo de produção e organização da vida em sociedade - e ao acesso desigual desses segmentos da população às ações e aos serviços de prevenção e cura de doenças, a implementação do SUS deve ser também orientada pelo princípio da eqüidade. A adoção do princípio da eqüidade implica reconhecer que necessidades diferenciadas da população sejam enfrentadas por meio de ações governamentais também diferenciadas (Malta, 2001).

A adoção do princípio da eqüidade requer, portanto, a utilização de critérios de discriminação positiva no processo de formulação de políticas públicas. Ou seja, remete ao entendimento que existem indivíduos ou grupos populacionais que são mais vulneráveis devido à sua condição sócio-econômica, e que por isso devem ser priorizados nos processos de intervenção estatal.

Universalidade, integralidade e eqüidade da atenção à saúde constituem, pois, a finalidade ético-política do sistema de saúde expressa em contribuição para a melhoria das condições de saúde e vida da população brasileira (Silva et al., 2003).

Com efeito, para Cecílio (2001) esses três princípios - universalidade, equidade e integralidade - formam um conceito tríplice, entrelaçado, quase um signo, capaz de expressar com todo vigor a luta por cidadania, justiça e democracia, consubstanciada no ideário da Reforma Sanitária brasileira. A visão (ampliada) da idéia de integralidade seria capaz de incorporar as propostas de integralidade (no seu entendimento corrente), eqüidade e universalidade, constituindo-se, portanto, na essência da política pública de saúde.

Parte-se da premissa de que não existe a possibilidade de construção da integralidade e da eqüidade - os verdadeiros objetivos da política de saúde, que vão além do consumo de determinadas tecnologias e serviços sem a garantia do acesso universal a todos os níveis de atenção. Essa perspectiva implica o reconhecimento da ação recíproca existente entre a macro e a micropolítica de saúde. Isto porque, conforme o momento que vive o usuário, a tecnologia de saúde de que este necessita pode estar em uma unidade básica de saúde ou em algum serviço produtor de procedimentos mais 
sofisticados (como um hospital especializado, por exemplo) ou até mesmo pode depender de uma cooperação com outros setores da política governamental.

Para tanto, a busca pela integralidade e eqüidade deve ser orientada por meio de uma abordagem totalizante, ao repensar a organização do processo de trabalho, que inclui a gestão, o planejamento e a construção de novos saberes e novas práticas em saúde (Cecílio, 2001). Para esta reflexão sobre integralidade e eqüidade, o autor toma como "analisador" as necessidades de saúde.

Segundo Stotz (1991), as necessidades de saúde se situam no nível das necessidades sociais mais gerais. Ainda que sejam determinadas e constituídas social e historicamente, só poderão ser apreendidas em sua dimensão individual. Expressa-se, dessa forma, uma relação entre o individual e o coletivo, pois as necessidades de saúde espelham as mediações fundamentais da prática social. Tais mediações dizem respeito, por um lado, a um certo compartilhar dessas necessidades entre o sujeito individual e o grupo ao qual está dialeticamente referido (família, igreja, sindicato, organizações comunitárias, dentre outros), por outro, às mediações entre sujeitos individuais e coletivos e critérios de legitimação do poder político estatal. Nesse caso, a referência se daria em relação a um conjunto de necessidades consideradas como socialmente legítimas, implicando sua atenção por parte do Estado (Nunes, 1989).

Tomando como referência o caminho percorrido por Stotz, Cecílio (2001) propõe uma taxonomia das necessidades de saúde totalizadora da visão dos sujeitos individuais e coletivos organizada em quatro grandes conjuntos. O primeiro conjunto diz respeito a se ter 'boas condições de vida', entendida tanto no sentido mais funcionalista, que enfatiza os fatores externos, que determinam o processo saúde-doença, como nas formulações de autores de extração marxista, que enfatizam os diferentes lugares ocupados por homens e mulheres na sociedade capitalista, como as explicações mais importantes para adoecer e morrer. $\mathrm{O}$ segundo refere-se à necessidade de se ter acesso e se poder consumir toda tecnologia de saúde capaz de prolongar a vida. Um terceiro é relativo à insubstituível criação de vínculos (a)efetivos entre cada usuário e uma equipe e/ou um profissional, significando o estabelecimento de uma relação contínua no tempo, pessoal, calorosa e intransferível. O quarto e último conjunto concerne à necessidade de cada pessoa alcançar graus crescentes de autonomia no seu modo de levar a vida, onde informação e educação são, em saúde, apenas parte do processo, implicando a possibilidade de reconstrução, pelos sujeitos, dos sentidos de sua vida, e incluindo aí a luta pela satisfação de suas necessidades, de forma mais ampla possível.

De acordo com este autor, a escuta das necessidades de saúde tem o potencial de ampliar a capacidade e as possibilidades de intervenção por par- 
te dos trabalhadores de saúde em relação aos problemas daqueles que procuram os serviços de saúde.

Como os problemas de saúde são complexos, requerem para o seu enfrentamento, conforme destacam Merhy \& Franco(2003), a utilização de múltiplos saberes e múltiplas práticas e o trabalho em equipe multiprofissional, no sentido da mudança do foco dos serviços e das ações de saúde para as necessidades individuais e coletivas dos usuários, para o cuidado, para a produção de relações de acolhimento, vínculo e responsabilização entre os trabalhadores e esses usuários.

Para que uma nova prática, coerente com os princípios defendidos pelo SUS, aconteça efetivamente, faz-se necessário transformações no âmbito da formação profissional em saúde, pois não é possível fazer avançar o SUS com a reprodução de práticas alienantes e descompromissadas com a integralidade da atenção.

\section{A necessidade de mudança na formação dos profissionais de saúde: aspectos pedagógicos}

A formação do profissional de saúde tem sido alvo crescente de debate no cenário nacional. Critica-se o modelo flexneriano de formação, desenvolvido por meio de currículos arcaicos, centrados na doença, na hegemonia médica, na atenção individual e na utilização intensiva de tecnologia; marcados pela dissociação entre teoria da prática; e voltados para um desempenho profissional impessoal e descontextualizado e para a formação do cidadão produtivo, onde o mercado funciona como princípio organizador do conjunto da vida coletiva.

A partir da década de 50 começaram a surgir as críticas ao paradigma flexneriano e as tentativas de introduzir novas ênfases nos modelos de ensino das profissões da saúde, reforçando dimensões preventivas, psicossociais, comunitárias e ambientais (Chaves e Kisil, 1999).

Acumulam-se os argumentos favoráveis à necessidade de mudar a educação dos profissionais de saúde, propondo-se um novo paradigma capaz de reorientar as relações entre estes profissionais e a comunidade e de redefinir o peso e o papel do setor de prestação de serviços de saúde nesse processo. O paradigma da construção social da saúde apóia-se no fortalecimento do cuidado, na ação intersetorial e na crescente autonomia das populações em relação à saúde (Mendes, 1996).

Feuerwerker (2001) destaca que existe quase uma exigência social para que se mude o processo de formação, a fim de produzir profissionais diferentes, com formação geral, capazes de prestar uma atenção integral e humanizada às pessoas. Tais profissionais devem ser capazes de trabalhar em 
equipe e tomar decisões considerando não somente a situação clínica individual, mas o contexto em que vivem os pacientes, os recursos disponíveis e as medidas mais eficazes.

Evitando-se a adoção de um modelo de formação, são muitos os movimentos e as experiências em andamento a fim de construir uma educação crítica, que concebe o homem como sujeito integrado às forças sociais e não como submisso às forças produtivas. Deste modo, os mecanismos de educação devem ser condizentes com tais transformações, para que possa promover a formação de um profissional propositivo frente às demandas impostas pela necessidade de transformação da política de saúde, como uma forma e potência de explicitar toda a complexidade do processo de trabalho em saúde, assim como possibilitar a apreensão de novas habilidades necessárias à construção de uma prática mais qualificada e transformadora.

Considerando essa pretensão, é fundamental o desenvolvimento de uma visão sistêmica da formação, mediada por uma prática integradora, que busque aproximação e interação entre diferentes áreas de conhecimentos, projetos, atores e segmentos sociais. Essa formação deve ter como perspectiva ampliar a capacidade dos profissionais de escutar as necessidades de saúde e de contextualizar e resolver problemas de saúde, como também a de construir projetos sociais alternativos e reivindicar espaços 'sócio-políticos', assegurando, assim, seu poder decisório e a 'manutenção de identidade cultural'.

Para tanto, há a necessidade de se articular uma nova pedagogia, uma nova racionalidade na formação de profissionais de saúde, feita de sujeitos em relação, que aprendem a partir da própria realidade a desenvolver o potencial de criação, aprimorando na relação intrínseca que se estabelece entre o compreender e o construir saúde a sua prática. Aqui, entendemos, por 'compreensão', um compromisso de participação ativa no enfrentamento dos problemas de saúde e, por 'construção', a consolidação das possibilidades de articulação dos saberes científicos, com os saberes dos usuários dos serviços de saúde numa ação conjunta e solidária capaz de fazer história.

Ensinar adquire o significado não apenas de execução do que é próprio da profissão, mas o de saber repensar a profissão e de reconstrui-la, inovála, gerando capacidade de questionar a prática, o cotidiano do trabalho, o próprio exercício profissional. Onde inovar assume o sentido de reinventar os saberes e as competências, ter a capacidade de monitorar a própria história, participar de um processo de desconstrução e reconstrução de uma realidade (Plantamura, 2003).

Nesse sentido, a aprendizagem orientada às experiências parece adequar-se à perspectiva da integralidade do ensino. A experiência é uma categoria central e entendida em sua carga de compreensão e reação diante da realidade e em sua dimensão de coletividade. O ser humano precisa conhecer para compreender o mundo em que vive e poder atuar em cooperação 
com os demais homens numa base de solidariedade. Para isto, é preciso ensinar através de uma práxis pedagógica que reflita inicialmente as experiências concretas dos alunos.

A concepção pedagógica crítico-reflexiva, especialmente a problematização, constitui instrumental adequado por propiciar a articulação de ações internas e externas ao serviço e por desafiar os diferentes atores sociais para uma postura de mudança e problematização de suas próprias práticas, com ênfase na autonomia. Trabalhar sobre problemas abre espaço para o trabalho interdisciplinar, possibilitando tratar de maneira mais integral temas, conteúdos e ações.

A problematização é uma metodologia de ensino, estudo e trabalho, que intencionalmente utiliza os problemas para o desenvolvimento do aprender e do ensinar, aumentando a capacidade do aluno em detectar e resolver os problemas reais e descobrir as soluções. A construção da aprendizagem se dá por etapas, partindo da realidade e nela retornando, transformando-a.

\section{A perspectiva da integralidade na formação profissional em saúde}

Gramsci (1982) já considerava a formação integral do homem, com capacidade de compreensão, análise e escolha. A escola seria uma das atividades políticas mais importantes e essenciais, preparando pessoas capazes de construir uma vida melhor para si mesmas e deixá-las em melhor condição para o exercício da cidadania e da solidariedade, educando na prática social para agir na sociedade. Para Gramsci, a formação do homem não fica apenas no plano individual, mas objetiva essencialmente o coletivo.

A adoção da integralidade como eixo orientador da formação de profissionais de saúde resgata o conceito de omnilateralidade, ou seja, a necessidade de considerar a totalidade na análise de qualquer fenômeno em questão, exigindo uma compreensão integral do mundo e das relações sociais e políticas.

Segundo Xavier (2002), um dos grandes desafios para a formação de profissionais de saúde é a construção de uma cultura, tanto nos serviços quanto na escola, que parta da compreensão totalizante do processo de trabalho e do pressuposto de que os trabalhadores são sujeitos desses processos. Por muito tempo, a qualificação profissional se restringia ao âmbito da instituição de ensino, sendo o cenário da prática e dos serviços tomados apenas como coadjuvantes desse processo.

O papel da educação é a formação do homem e o que caracteriza a realidade humana é o trabalho. Pelo trabalho o homem transforma a natureza, ajustando-a às suas necessidades (Saviani, 2003). Assim, busca-se construir, no âmbito do SUS, uma práxis pedagógica que seja capaz de explicitar a 
complexidade do processo de trabalho em saúde, que objetive romper com as perspectivas instrumental, fragmentária e produtivista que caracterizam a atual formação profissional.

Cecim e Armani (2002) destacam que os desafios atuais na formação e no desenvolvimento dos trabalhadores de saúde está em aprender a não dissociar atenção individual às doenças e aos adoecimentos da vigilância à saúde; não dicotomizar qualidade de vida do andar da vida; não dissociar os grupos de trabalhadores (da gestão, da atenção e da vigilância); não perder o conceito de atenção integral à saúde; realizar o trabalho educativo junto à população como um trabalho de aprendizagem; e aceitar que há incerteza na definição dos papéis profissionais, onde há alternância de saberes e práticas de cada núcleo constituidor das profissões de saúde e do campo da atenção integral à saúde.

Nesse sentido, Ramos (2001) diz que a preparação do trabalhador passou a exigir processos educativos mais amplos e problematizadores, que visem ao desenvolvimento de conhecimentos de caráter global, indo além da aquisição formal de conhecimentos acadêmicos e construindo saberes a partir das experiências vividas no trabalho, na escola e na vida.

Conforme nos fala Carvalho e Motta (2003), o sistema formador deve incorporar o mundo do trabalho como eixo produtor de conhecimentos e definidor de demandas educacionais, de modo que as experiências do trabalho passam a ser o ponto de partida para a análise crítica e a tomada de decisões em saúde.

Destaca-se que o trabalho é assumido como princípio educativo, e não apenas como instrumento de aprendizado, não se reduzindo ao mundo da necessidade (atividade de produção material), mas envolvendo o mundo da liberdade (dimensões sociais, estéticas, culturais, artísticas, de lazer...).

A reconciliação entre o universo acadêmico e o mundo do trabalho introduz repercussões significativas na formação de profissionais para área de saúde, levando à superação da aprendizagem formalista, cuja prática baseiase na simulação de situações de trabalho idealizadas, que não levam em consideração a complexidade e incerteza das situações concretas de saúde-adoecimento. Contudo, a simples introdução do aluno na prática por si só não gera uma formação crítica e transformadora. É preciso interrogar quais os contextos formativos capazes de gerar uma prática inovadora, critica e reflexiva.

Conforme destaca Feuerwerker (2001), o 'cenário de aprendizagem' exerce papel fundamental no processo de transformação do ensino, dizendo respeito não somente ao local em que se realizam as práticas, mas aos sujeitos nelas envolvidos, à natureza e ao conteúdo do que se faz. O conceito relaciona-se à incorporação e à inter-relação entre métodos didáticos e pedagógicos, áreas de práticas e vivências, utilização de tecnologias e habilidades cognitivas e psicomotoras e inclui a valorização dos preceitos morais e 
éticos orientadores de condutas individuais e coletivas. Os cenários de aprendizagem consideram os processos de trabalho, o deslocamento do sujeito e do objeto do ensino e revisam a interpretação das questões referentes à saúde e à doença, considerando-se sua dinâmica social.

Esta compreensão não deve, contudo, levar o aluno a um ajustamento ao mundo do trabalho, mas a uma postura construtivista e histórica, a qual dá importância aos sujeitos em relação, seus objetivos e possibilidades na construção de soluções criativas e cooperativas, desenvolvendo neste capacidades de iniciativa, de encontrar solução para os problemas complexos do viver.

Precisamos considerar a importância dos conhecimentos científicos produzidos academicamente. A maneira como a escola prepara os profissionais de saúde é certamente uma questão crítica, contudo seu papel é insubstituível na formação e na produção de conhecimentos, em consonância com a concepção do complexo promoção-saúde-doença-cuidado.

A complementaridade de papéis entre esses dois importantes setores, saúde e educação, é evidente. A ampliação da capacidade de interlocução entre eles é um dos principais desafios para o processo de transformação.

Ceccim e Armani (2002) descrevem que o contato continuado dos profissionais com os usuários das ações e dos serviços de saúde, atuando em equipes com trabalho coletivo e co-responsável, permite o cruzamento dos saberes e o desenvolvimento de novos perfis profissionais. Deste modo, às instituições de ensino na saúde compete viabilizar a integração de todos os cursos da área às diretrizes do SUS, incluindo na formação profissional as noções de atenção integral à saúde, de perspectiva de trabalho em equipe e o debate das políticas públicas de saúde, superando o tradicional treinamento de recursos humanos ou a capacitação para cumprir programas.

Assim, o estabelecimento de parceria entre órgão formador, serviços de saúde e organizações comunitárias é fundamental para a formação do profissional de saúde, não só pela característica prática da profissão, mas pela necessidade de promover entre os profissionais uma consciência crítica da realidade, desenvolvendo assim o compromisso da educação com a construção do saber para a melhoria da qualidade de vida e de saúde da população. A prática cooperativa com os serviços permite trazer novos temas e desafios ao processo de ensino e de produção de conhecimento, além de ajudar a reorientar o próprio modelo assistencial. Nesse contexto, a prática pedagógica adquire maior amplitude conceitual e metodológica, ultrapassando a perspectiva burocrática, para dar lugar à gestão democrática. 


\section{Considerações finais}

Os desafios da formação dos profissionais de saúde estão ligados aos desafios do sistema de saúde. Ambos devem buscar uma reorientação dos modos de cuidar e de promover a saúde, tendo em vista o processo de responsabilização e comunicação dialógica entre governantes, gestores, usuários, profissionais de saúde, formadores e alunos, visando à integralidade da atenção em saúde.

A interlocução entre instituições e atores sociais é a chave para a integração das ações, e a escuta das necessidades de saúde a ferramenta básica de que dispõe o profissional para o acolhimento das demandas por cuidados em saúde.

A 'pedagogia da integralidade', pautada por um princípio educativo inerente à garantia da saúde como direito e como serviço, constitui uma estratégia para diminuir as fronteiras atuais entre trabalho-ensino-serviço-sociedade, tornando-as mais permeáveis aos valores democráticos e emancipatórios.

\section{Notas}

1 Professor da Escola Politécnica de Saúde Joaquim Venâncio da Fundação Oswaldo Cruz (EPSJV/Fiocruz), Mestre em Saúde Coletiva pelo Instituto de Medicina Social da Universidade do Estado do Rio de Janeiro (IMS/Uerj). <zepa@fiocruz.br>

2 Professora Titular de Enfermagem Psiquiátrica da Escola de Enfermagem da UFF. Doutora em Enfermagem pela UFRJ. <claumara@vr.microlink.com.br>

3 Segundo Merhy (2002, p. 48-49), “as máquinas-ferramenta são expressões tecnológicas duras das tecnologias-saberes (leve-duras) e, como equipamentos tecnológicos, não têm razão (instrumental) por si, pois quem as torna portadoras dessa intencionalidade racional-instrumental é o trabalho vivo em ato com seu modo tecnológico (seu modelo de produção) de agir e como expressão de certas relações sociais e não outras; (como no caso dos equipamentos tecnológico do tipo máquinas, normas, estruturas organizacionais)".

4 São os saberes bem estruturados que operam nos processos de trabalho em saúde, como a clínica médica, a clínica psicanalítica, a epidemiologia, o taylorismo, o fayolismo (Merhy, 2002). 
5 O trabalho em saúde é centrado no trabalho vivo em ato permanentemente, um pouco semelhante ao trabalho em educação, não podendo, como em outros modelos produtivos (o fabril, por exemplo), ser capturado pelo trabalho morto expresso nos equipamentos ou nos saberes bem estruturados como as tecnologias organizacionais, pois o seu objeto não é plenamente estruturado, e suas tecnologias de ação mais estratégicas configuram-se em ato, operando como tecnologias de relações, de encontro de subjetividades, para além dos saberes tecnológicos estruturados, comportando um grau de liberdade significativa na escolha do modo de fazer essa produção (Merhy, 2002).

6 Merhy (2002, p. 50-51) usa esse termo com sentido semelhante ao de Deleuze "para designar o que se produz nas relações entre 'sujeitos', no espaço das suas interseções, que é um produto que existe para os 'dois' em ato e não tem existência sem o momento da relação em processo, e na qual os intercessores se colocam como instituintes na busca por novos processo, mesmo um em relação ao outro".

7 Segundo Merhy e Franco (2003), a reestruturação produtiva na saúde caracterizase por um certo modo de produção, diferente de um modelo adotado anteriormente, que impacta os processos de trabalho sem, entretanto, operar uma mudança significativa na correlação entre trabalho morto e trabalho vivo, a ponto de proporcionar uma hegemonia do segundo sobre o primeiro, o que configuraria uma transição tecnológica na saúde.

\section{Referências}

BRASIL. 1988. Constituição Brasileira. Brasília: Imprensa Oficial.

CAMPOS, Gastão. W. S. 1999. Educação médica, hospitais universitários e o Sistema Único de Saúde. Cad. Saúde Pública, v. 15, n. 1, p. 187-194.

1991. A saúde pública e a defesa da vida. São Paulo: Hucitec.

CARVALHO, Maria Alice; MOTTA, José Inácio. 2003. Currículo baseado em competência na área de saúde pública: avaliando uma proposta metodológica. Rio de Janeiro: Ensp/Fiocruz. (Mimeo).

CECCIM, Ricardo; ARMANI, Teresa B. 2002. Gestão da educação em saúde coletiva e gestão do Sistema Único de Saúde. In: FERLA, A.; FAGUNDES, S. (orgs.). Tempo de inovações: a experiência da gestão na saúde do Rio Grande do Sul. Porto Alegre: Ed. da Casa, p. 143-161.

CECÍLIO, Luiz C. O. 2001. As necessidades de saúde como conceito estruturante na luta pela integralidade e eqüidade na atenção em saúde. In: PINHEIRO, R.; MATTOS, R. (orgs.). Os sentidos da integralidade na atenção e no cuidado à saú- de. Rio de Janeiro: IMS-UERJ, p. 113126.

CHAVES, Mario; KISIL, Marcos. 1999. Origens, concepção e desenvolvimento. In: ALMEIDA, M; FEUERWERKER, L; LIANOS, C. (orgs.). A educação dos profissionais de saúde na América Latina: teoria e prática de um movimento de mudança. São Paulo: Hucitec, p. 1-16.

DELUIZ, Neise. 2001. Qualificação, competência e certificação: visão do mundo do trabalho. Revista Formação, v. 1, n.2., p. 5-15.

FEUERWERKER, Laura; SENA, Roseni. 1999. A construção de novos modelos acadêmicos, de atenção à saúde e de participação social. In: ALMEIDA, M; FEUERWERKER, L; LIANOS, C. (orgs.). A educação dos profissionais de saúde na América Latina: teoria e prática de um movimento de mudança. São Paulo: Hucitec, p. 47-82.

FEUERWERKER, Laura. 2001. Estratégias para a mudança da formação dos profissionais de saúde. Cadernos CE, v. 2, n. 4, p. 11-23. 
FRIGOTTO, Gaudêncio; CIAVATTA, Maria. 2003. Educar o trabalhador cidadão produtivo ou o ser humano emancipado? Trabalho, Educação e Saúde, v. 1, n. 1, p. 45-60.

GRAMSCI, Antônio.1982. Os intelectuais e a organização da cultura. 4a ed. Rio de Janeiro: Civilização Brasileira.

MALTA, Deborah. C. 2001. Buscando novas modelagens em saúde: as contribuições do Projeto Vida e do Acolhimento na mudança do processo de trabalho na rede pública de Belo Horizonte, 1993-1996. Tese de Doutorado em Saúde Coletiva, Campinas: DMPS/FCM/Unicamp.

2004. Parecer sobre o Documento de Referência para a Área de Atenção à Saúde da Escola Politécnica Joaquim Venâncio.Rio de Janeiro: Escola Politécnica de Saúde Joaquim Venâncio, Fundação Oswaldo Cruz. (Mimeo).

MENDES, Eugênio V. 2001. Os grandes dilemas do SUS: tomo I. Salvador: Editora Casa da Qualidade.

. V. 1996. Uma agenda para a saúde. São Paulo: Hucitec.

1993. Distrito Sanitário: o processo social de mudanças de práticas sanitárias do Sistema Único de Saúde. São Paulo: Hucitec.

MENDES-GONÇALVES, Ricardo Bruno. 1979. Medicina e história: raízes sociais do trabalho do médico. Dissertação de Mestrado, São Paulo: Faculdade de Medicina, Universidade de São Paulo.

MERHY, Emerson. E; FRANCO, Thulio B. 2003. Por uma composição técnica do trabalho em saúde centrada no campo relacional e nas tecnologias leves: apontando mudanças para os modelos tecnoassistenciais. Saúde em Debate, v. 27, n. 65, p. 316-323.

MERHY, Emerson E. 2002. Saúde: a cartografia do trabalho vivo. São Paulo: $\mathrm{Hu}-$ citec.

1997. O SUS e um dos seus dilemas: mudar a gestão e a lógica do processo de trabalho em saúde (um ensaio sobre a micropolítica do trabalho vivo). In: FLEURY, S (org.). Saúde e democracia: a luta do CEBES. São Paulo: Lemos Editorial, p. 124-141.
MS (Ministério da Saúde). 2003. Politicas de educação e desenvolvimento para o SUS: caminhos para a educação permanente em saúde. Disponível em: <http://portal.saude.gov.br/saude/arquivos/pdf/ed ucacao_permanente_tripartite.pdf $>$. Acesso em: 1 set. 2004.

NUNES, Edison. 1989. Carências urbanas, reivindicações sociais e valores democráticos. Lua Nova: revista de cultura e política, n. 17, p. 67-91.

PLANTAMURA, Vitangelo. 2003. Presença histórica, competências e inovação em educação. Petrópolis, RJ: Vozes.

RAMOS, Marise. 2001. Qualificação, competências e certificação: visão educacional. Revista Formação, v. 1, n. 2, p. 17-26.

SENNA, Mônica C. M. 2002. Eqüidade e política de saúde: algumas reflexões sobre o Programa Saúde da Família. Cadernos de Saúde Pública, v. 18 (supl.), p. 203211.

SAVIANI, Dermeval. 2003. O choque teórico da politecnia. Trabalho, Educação e Saúde, v. 1, n. 1, p. 131-152.

STOTZ, Eduardo N. 1991. Necessidades de saúde: mediações de um conceito (contribuição das ciências sociais para a fundamentação teórico-metodológica de conceitos operacionais da área de planejamento em saúde). Tese de Doutorado em Saúde Pública, Rio de Janeiro: Escola Nacional de Saúde Pública.

SILVA, José Paulo V.; PINHEIRO, Roseni; MACHADO, Felipe R. 2003. Necessidades, demanda e oferta: algumas contribuições sobre os sentidos, significados e valores na construção da integralidade na reforma do setor saúde. Saúde em Debate, v. 27 , n. 65 , p. 234-242.

XAVIER, Caco. 2002. Formação profissional em saúde. Radis: comunicação em saúde, n. 3, p. 10-17.

Recebido em 20/05/2004

Aprovado em 19/07/2004 